\title{
Mechanical Performance Analysis of the Columns Strengthened with Prestressed CFRP Sheets
}

\author{
Yamin $\mathrm{Yi}^{1, \mathrm{a}^{*}}$, Donghui Cheng ${ }^{2, \mathrm{~b}}$ \\ ${ }^{1}$ School of Civil Engineering, Hunan University of Technology, Taishan Road, Zhuzhou 412007, \\ P.R. China \\ ${ }^{2}$ School of Civil Engineering, North East Forestry University, Hexing Road, Harbin 150040, P.R. \\ China

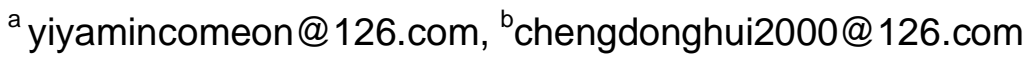

Keywords: Prestressed CFRP sheets; Strengthened; Concrete columns

Abstract. In order to study the mechanical performance on concrete columns strengthened with prestressed CFRP sheets, three groups of twelve concrete columns were made, according to the reinforcement ratio and tensile stress of CFRP sheets. Then the axial compression test under static load was completed and the experimental data was obtained. Moreover, the collapse state, ultimate bearing capacity and the steel and concrete strain analysis were studied. The results show that the prestressed CFRP sheets could put off the appearance and development of initial cracks, limit the lateral deformation of the concrete, improve the ultimate strength and compressive strain of the concrete. At the same time the longitudinal reinforcement give full play to the performance of plastic deformation. The columns strengthened with prestressed CFRP sheets were simulated by ANSYS software, the result shows that the test and the analysis value are in good agreement.

\section{Introduction}

In recent years, with the development of science and technology, the Carbon Fiber Reinforced Plastics (called for short as CFRP) become the focus in the civil engineering. Compared with common reinforced concrete reinforcement material, CFRP sheets have the advantages in unidirectional high tensile strength, light quality, corrosion resistance and so on, which makes the stick of CFRP reinforced concrete construction technology widely used at home and abroad, [1-4]. However, the test shows that the reinforcement method has some defects, such as lack of ductility, hysteresis of stress, elastic modulus and anti-fatigue performance. In order to solve these deficiencies, giving the prestressing force to CFRP sheets before pasting can change the mechanical properties of the CFRP and give full play to the advantages of high strength of CFRP (5-9).

The research of prestressed CFRP reinforced concrete column is very few At present, according to this situation, this paper carried out the experimental study of prestressed CFRP reinforced concrete column and the finite element analysis.

\section{Test Plan}

Tension device design In order to solve the problem of tensioning and anchorage of CFRP, based on the mechanical properties of CFRP, a set of suitable for the concrete compression member tension prestressed CFRP device was developed through trial and error. The tension device consists of two parts: the hoops and the tension system. The hoops have sufficient strength and stiffness to withstand the deformation and stress .

Figure 1 is tension figure, the device's working principle is: one end of the prestressing CFRP paste on the one side of column with epoxy resin, which make the the paste length satisfy the tension force, then the hoops fix on the both sides of CFRP. Pull the screw through the floor and pressure sensor after connection of screw and steel roller. Put the CFRP around the column a circle, and the other end of CFRP round steel roller and paste a certain length. Then the CFRP is tensioned after the epoxy resin dry. The screw nut is tightened by wrench and the CFRP is fastened by screw, so as to realize the tension of CFRP, the tensile stress is monitored by sensor. 


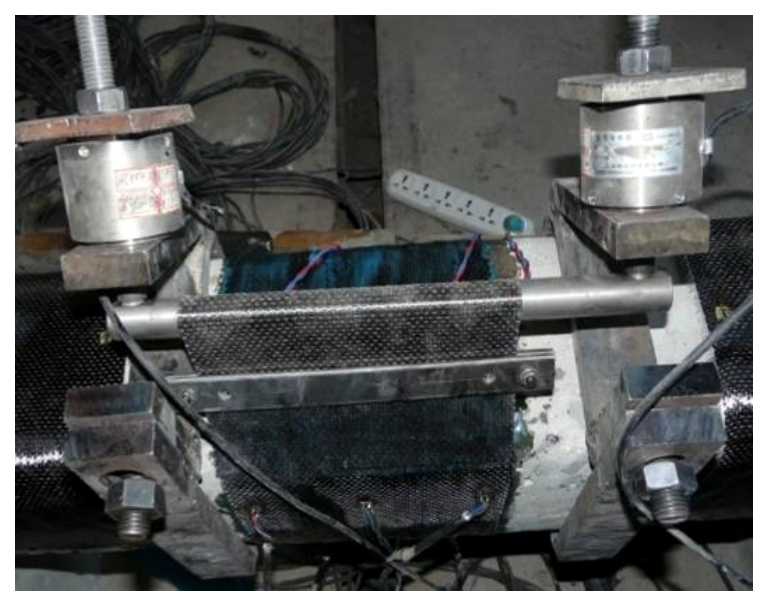

Fig. 1 the tension figure

Test column design three groups of twelve concrete square columns were made, each group include an ordinary concrete column and three prestressed CFRP sheets reinforced columns. The cross section size is $200 \times 200 \mathrm{~mm}$, column height is $1000 \mathrm{~mm}$ and the concrete cover thickness is $25 \mathrm{~mm}$. Test column is symmetrical reinforcement, the stirrups is $6 \mathrm{~mm}$ in diameter. The CFRP width is 200 $\mathrm{mm}$, The CFRP is pasted on the exposed concrete after the concrete column strengthened with prestressed CFRP along column high direction. Each test reinforcement ratio of column and CFRP tension stress are shown in table 1.

Table1 parameters of the specimens

\begin{tabular}{ccc}
\hline nubmer & Ratio $\rho(\%)$ & Control stress $(\mathrm{MPa})$ \\
\hline DBZ1 & 1.13 & 0 \\
YJGZ1-B & 1.13 & 200 \\
YJGZ1-B & 1.13 & 500 \\
YJGZ1-C & 1.13 & 800 \\
DBZ2 & 2.01 & 0 \\
YJGZ2-A & 2.01 & 200 \\
YJGZ2-B & 2.01 & 500 \\
YJGZ2-C & 2.01 & 800 \\
DBZ3 & 3.14 & 0 \\
YJGZ3-A & 3.14 & 200 \\
YJGZ3-B & 3.14 & 500 \\
YJGZ3-C & 3.14 & 800 \\
\hline
\end{tabular}

In the table, DBZ represents ordinary concrete column. YJGZ represents the prestressed CFRP reinforced column, and the first number is reinforcement ratio, the second number is the stress level of the tension CFRP. Such as YJGL1-A, which means that the reinforcement ratio is $1.13 \%$ and the control stress is $200 \mathrm{MPa}$.

Test column reinforcement According to the characteristics of the tension device, the strengthened steps are: chamfer processed, surface treatment, bottom glue brushed, one end of CFRP sheets fixed, CFRP sheets tensioned, epoxy resin glue brushed and maintenance. The strengthened columns are shown in figure 2. 


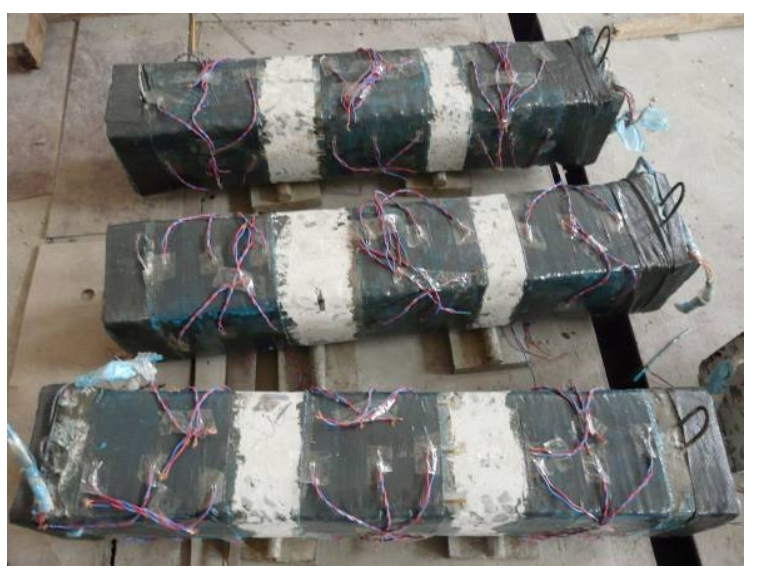

Fig.2 the specimens was tensioned

Test and measurement The CFRP sheets and prestressed CFRP sheets strain, longitudinal reinforcement and concrete longitudinal strain are tested. The strain gauge paste positions are shown in figure 3.

The loading method is in accordance with the 《standard for test method of mechanical properties on ordinary concrete》(GB50081-2002). Per-class $20 \mathrm{KN}$ is loaded, and per-class $5 \mathrm{kN}$ loaded close to the limit load which is done until test cloumn fail. The loading is loaded slowly and uniformly, and per level load has Pause $2 \sim 3$ min pause. The crack propagation, displacement reading, the strain and the experimental phenomenon at per level load are recorded.

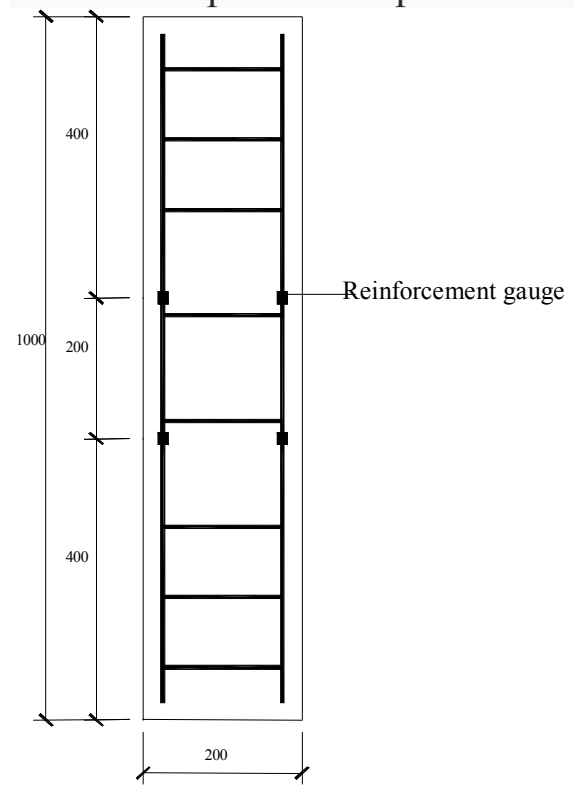

(a) Reinforced strain gauge arrangement

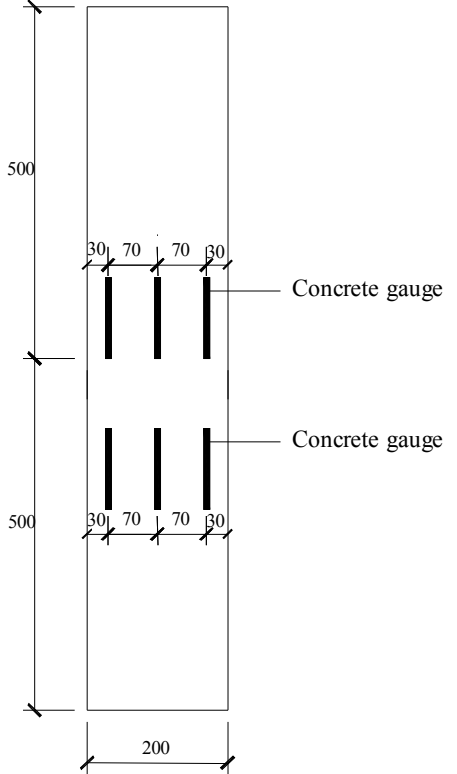

(b) concrete strain gauge arrangement

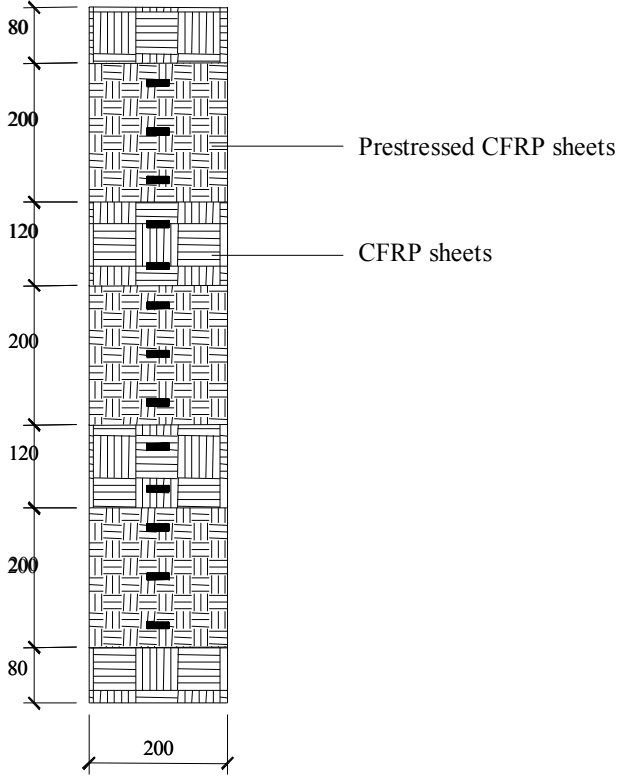

(c) common and prestressed CFRP sheets strain gauge on the layout

Fig. 3 measuring points arrangement of specimens

\section{Experimental phenomena}

The loading process of the columns can be roughly divided into three stages:in the first stage, the load is small, longitudinal and concrete strain are also small, the stress-strain curve are essentially coincident with ordinary concrete column, no cracks appear in concrete and the strain of the prestressed CFRP sheets develope slowly,which means the prestressed CFRP sheets have little restraint effect on the concrete at the beginning; In the second stage, with the increase of load, the strain of the concrete and steel increases rapidly, the lateral deformation of components increases 
gradually, cracks appear in the concrete, and the strain growth rate of the prestressed CFRP sheets and common CFRP sheets speed up, at the same time, the two began to deviate from the load-strain curve, this is mainly because the prestressed CFRP sheets can provide more constraints on concrete.In this stage, the cloumns have no exception in appearance, but the epoxy resin adhesive makes some noise;

In the third stage, with the further increase of load, the concrete cracks developed rapidly, and the lateral deformation increases significantly, the strain of the prestressed CFRP sheets increase dramatically along with larger internal noise.The load begin to slow down close to the limit state, axial and lateral deformation increase sharply, the load- strain curve of prestressed CFRP sheets is almost parallel to the $\mathrm{X}$ axis, but the column surface has no change, at the moment of destruction. the specimenes explode suddenly, the concrete spatter from the rupture direction, and the pointer of the press testing mechine turns back rapidly. The prestressed CFRP sheets are covered with a thick concrete viewed from the destruction of specimen, which shows a good bonding between concrete and prestressed CFRP sheets, and these two can work together before the failure .

\section{Conclusion}

(1) The test results show that the tension device has the advantages of simple operation, convenient practical and suitable for popularization and application in practical engineering.

(2) The prestressed CFRP can not only give full play to the performance of the high strength, at the same time it changes the method of using common CFRP reinforced stress hysteresis problems, and prompte the CFRP cloth by the passive stress into active stress.

\section{References}

[1] Duan Liping, shangxi Architecture,40(5):40-42. (2014)

[2]Cheng Donghui,Yi Yamin, China Railway Science, 32( 3):27-32(2011)

[3] Dong Jiangfeng, Wang Qingyuan, He Dong, etal. Journal of Applied Mechanics, 28 ( 5) :521-526(2011)

[4] Li Jianhui, Wu Qiang. FRP /CM , 6:73-77(2011)

[5]Cheng Donghui,Rong Wei,Zhou Wei. Journal of Harabin Institute of Technology,43(12) $143-148(2011)$

[6] Niu Xiangyang, Wang Quanfeng. Fujian Architecture \& Construction, 141( 3):54-55 (2010)

[7] Zhou Changdong,Bai Xiaobin,Zhao Feng,Lu Xilin,Li Chunlong. Journal of Building Structures, 34(2):131-140(2013)

[8]Bai Xiaobin.Study on the performance of circular concrete columns confined with lateral pre-tensioned FRP under axial load. Beijing, 2011 